\title{
Analysis of Forging Dies Coated with Tungsten Carbide through HVOF Processing
}

Vanessa Moura de Souza, Angela Selau Marques, Jorge Antônio Huff, Alexandre da Silva Rocha, and Luciano Kempski

GES (Group of Engineering Surface), Federated University of Rio Grande do Sul, Porto Alegre, Brazil

\begin{abstract}
In this paper we present a performance evaluation of thermal spraying coated hot forging dies conducted in a production line. The High Velocity Oxy-Fuel process was used for the deposition of a tungsten carbide coating, which is characterized by its optimal adherence and low porosity. A metallurgical characterization of the layer was previously done, in order to obtain reference information to assist in the interpretation of the practical tests results. The coated die allowed an increase in productivity of $37.5 \%$, besides better dimensional stability results through the process and legibility of printed numbers.
\end{abstract}

Key words: Hot forging, coating, die, surface.

\section{Introduction}

The forging process needs a great production flexibility, often working with a variety of products due to the current market being very dynamic and competitive. This reality consequently influences the working strategies related to the production of tools used for metal forming. The coatings are used to increase wear resistance and aim to extend the tools life $[1,2]$. The technique used to perform this process was the HVOF which belongs to a group of processes called thermal spraying where metallic or non-metallic materials, finely divided, are deposited in a molten condition under a prepared piece, forming a sprayed deposit [3]. The general concept of the Thermal Spraying Processes is shown, representatively in Fig. 1.

The process of thermal spraying by HVOF (high velocity oxy-fuel) has important advantages compared to other spraying processes apart from operating through a gun which provides high mobility and does not require a room with controlled atmosphere. Among

Corresponding author: Angela Selau Marques, M.Sc., research fields: mechanical conformation and surface engineering. these characteristics it is possible to mention $[4,5]$ :

- Low thermal attack to the substrate;

- Ability to deposition of different coatings with high adhesion;

- Low porosity compared to other spraying processes.

Thermal spray processes are directly related to particles temperature and velocity. In Fig. 2, we can see the representation of the coating particles when sprayed on the substrate, besides, it is possible to verify the lamellar structure oxides, inclusions, pores and voids that also occur during deposition [6].

The sprayed particles adhere to the substrate by a mechanism of chemical-metallurgical, physical and mechanical nature, depending on the heat source temperature and the speed imposed to the particles that due to successive depositions formed lamellar layers with oxides and pores. The structure of the coatings applied by thermal spraying is formed by overlapping lamellas, which are derived from the mirroring of the fused powder particles, when they impact with the substrate. The coating is formed by the occurrence of the same mechanism in the subsequent layers, as the solidification time is much smaller than the particle projection time [7]. 


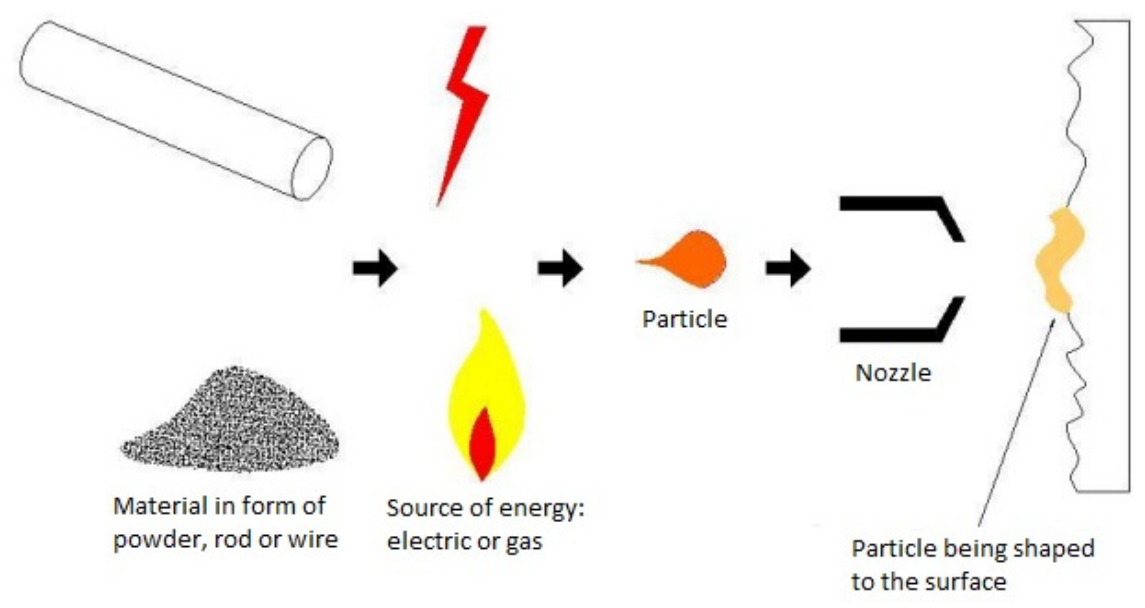

Fig. 1 Application scheme of the thermal spray processes.

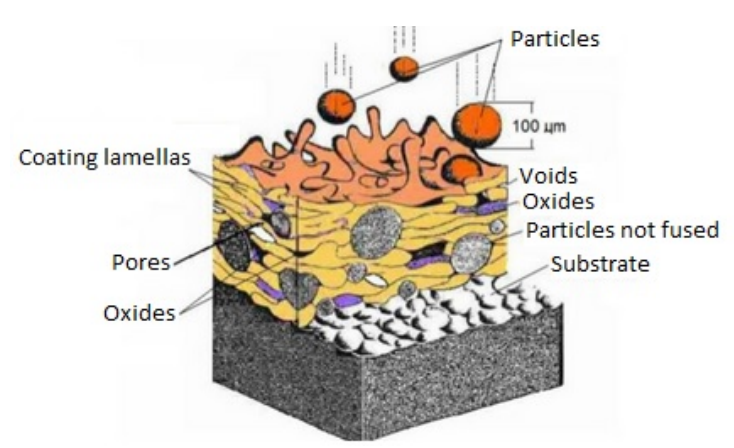

Fig. 2 Cross section of an HVOF sprayed coating.

\section{Materials and Methods}

For the characterization of the coating properties, hardness tests, metallographic analysis and chemical analysis via optical spectroscopy were carried out.

The samples used for the metallurgical characterization were discs with $40 \mathrm{~mm}$ in height and $90 \mathrm{~mm}$ in diameter, produced using the AISI H13 tool steel and with a hardness of 50HRC, being the same material and hardness specification used in the manufacturing practical case.

Evaluation of coating performance in hot forging process was carried out with the manufacturing of an automotive component used in the assembling of Cardan shafts. Fig. 3 shows a forged tube yoke.

A forging batch of 900 parts was programmed for a set of regular tools, and another batch of 900 parts for HVOF coated tools. Fig. 4 shows a picture of the standard forging die, while Fig. 5 shows the die after the thermal spray process.

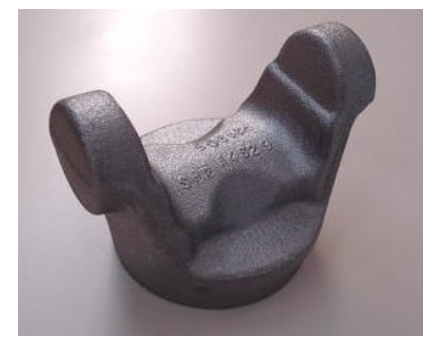

Fig. 3 Forged automotive part.

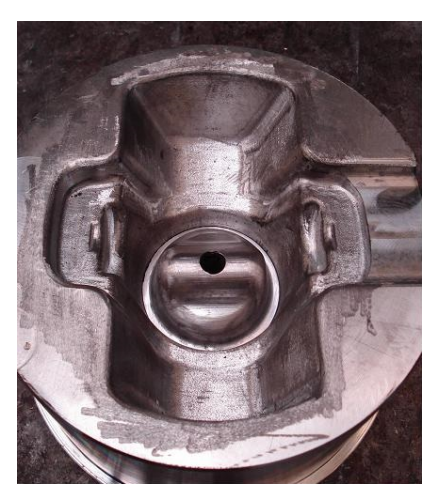

Fig. 4 The bottom die used for forging, finished with manual grinding.

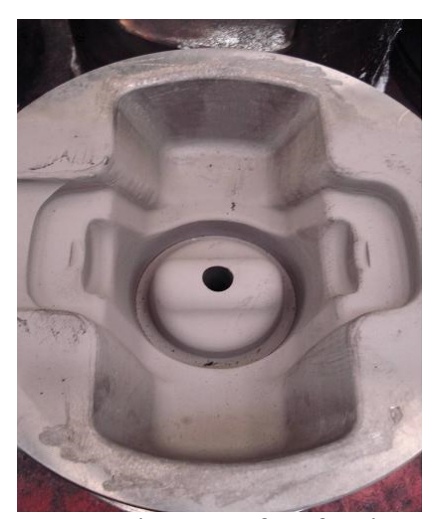

Fig. 5 The bottom die used for forging, finished with manual grinding and then thermal spray coated. 


\section{Results}

\subsection{Metallurgical Characterization}

Table 1 shows the results of the chemical analysis done on the upper surface of the coating in an optical spectroscopy equipment.

The results of the metallurgical characterization confirmed the chemical composition of the tungsten coating. The metallography results showed a typical thermal spray coating with a thickness of about 0.17 $\mathrm{mm}[8]$.

Fig. 6 presents the microstructure of the interface between the coating and the substrate, it is possible to observe the typical porosity of the coating process and its thickness of $0.17 \mathrm{~mm}$. Fig. 7 illustrates in detail the coating microstructure, formed by oxides and aggregated particles of previously molten and non-molten material [9].

Table 1 Coating chemical analysis.

\begin{tabular}{ll}
\hline Chemical element & Analysis* \\
\hline $\mathrm{C}$ & $0.1 \%$ \\
$\mathrm{Mn}$ & $0.09 \%$ \\
$\mathrm{Si}$ & $0.12 \%$ \\
$\mathrm{Al}$ & $0.01 \%$ \\
$\mathrm{Zn}$ & $2.2 \%$ \\
$\mathrm{Cr}$ & $6.2 \%$ \\
$\mathrm{Cu}$ & $0.01 \%$ \\
$\mathrm{~W}$ & $81.2 \%$ \\
$\mathrm{Ni}$ & $0.09 \%$ \\
$\mathrm{Co}$ & $9.90 \%$ \\
$\mathrm{Mo}$ & $0.08 \%$ \\
\hline
\end{tabular}

*Mass percentage results.

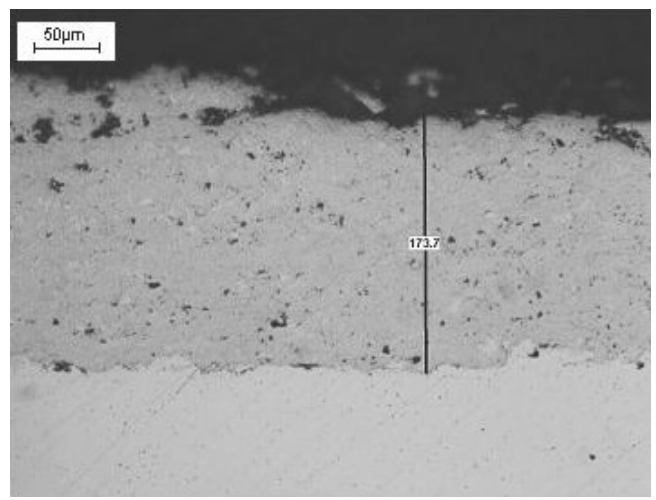

Fig. 6 Micrograph of the interface between the coating and the substrate.

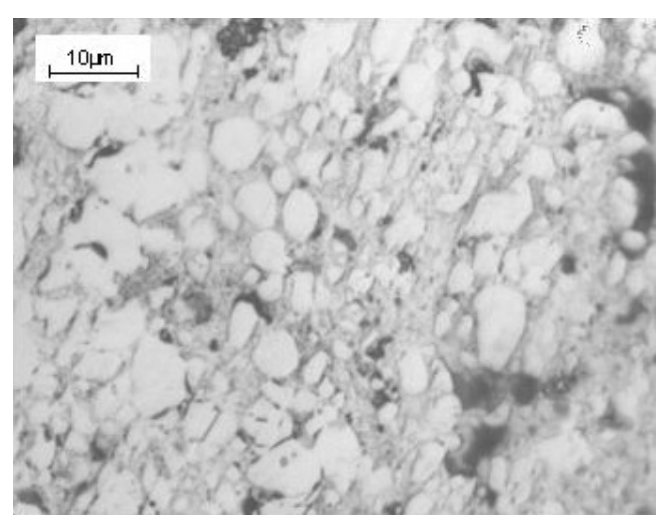

Fig. 7 Coating micrograph in detail.

Table 2 shows the results of 8 microhardness measurements carried out with a length of $0.4 \mathrm{~mm}$ along the coating. Due to the coating porous surface, which makes it difficult to measure its microhardness, it was necessary to do several readings [10].

The measurements values have some variation, however it is possible to identify an upward trend from the surface, as shown by the line with the average of the eight measurements in Fig. 8.

The variation found in the microhardness measurements is related to the porosity and the coating deposition condition.

Table 3 displays the microhardness measurement results obtained after the coating. The first column contains the distance in which the readings were made, and for each one of these distances an average hardness was calculated. As there was no significant difference between the distances, we can observe that the hardness is homogeneous across the sample surface [11].

Table 2 Coating microhardness measurements.

\begin{tabular}{lllll}
\hline Length & $0.4 \mathrm{~mm}$ & $0.8 \mathrm{~mm}$ & $0.12 \mathrm{~mm}$ & $0.16 \mathrm{~mm}$ \\
\hline Reading 1 $\mathrm{HV}_{0,2}$ & 801 & 808 & 877 & 901 \\
Reading 2 $\mathrm{HV}_{0,2}$ & 827 & 869 & 859 & 897 \\
Reading 3 $\mathrm{HV}_{0,2}$ & 842 & 809 & 862 & 868 \\
Reading 4 HV & 819 & 801 & 852 & 903 \\
Reading 5 HV & 830 & 832 & 866 & 896 \\
Reading 6 HV & 849 & 850 & 893 & 879 \\
Reading 7 HV & 813 & 841 & 889 & 856 \\
Reading 8 $\mathrm{HV}_{0,2}$ & 832 & 868 & 867 & 907 \\
Average $\mathrm{HV}_{0,2}$ & 827 & 836 & 871 & 888 \\
Standard deviation & 15,482 & 26,753 & 14,491 & 18,531 \\
\hline
\end{tabular}




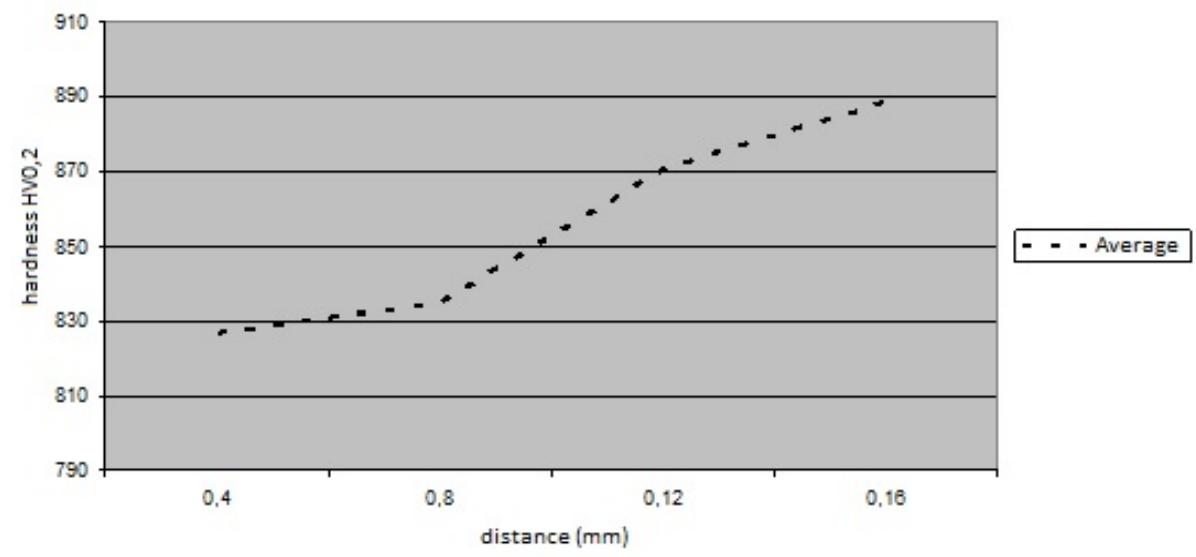

Fig. 8 Average of 8 coating microhardness measurements.

Table 3 Coating microhardness measurements.

\begin{tabular}{llll}
\hline Distance (mm) & $0-30$ & $30-60$ & $60-90$ \\
\hline Reading 1 HRc & 66 & 65 & 65 \\
Reading 2 HRc & 64 & 67 & 65 \\
Reading 3 HRc & 65 & 65 & 65 \\
Reading 4 HRc & 67 & 67 & 66 \\
Reading 5 HRc & 65 & 66 & 66 \\
Average HRc & 65.4 & 66 & 65.4 \\
Standard deviation & 1,140 & 1,000 & 0,548 \\
\hline
\end{tabular}

\subsection{Wear Test-Pin-on-Disc Method}

In order to evaluate the surface treatment performance a pin-on-disc test was performed. This test provides information regarding friction and wear resistance under sliding conditions. This condition commonly occurs in operations with tools where there is a contact between the workpiece (simulated by the ball) and the tool (simulated by the disc).

The results presented in Figs. 9 and 10 show that the coefficient of friction was higher on the regular surface with an average value of 0.66 while the coated one had an average of 0.42 . This difference indicates that the coating has good tenacity, good substrate adhesion and high hardness.

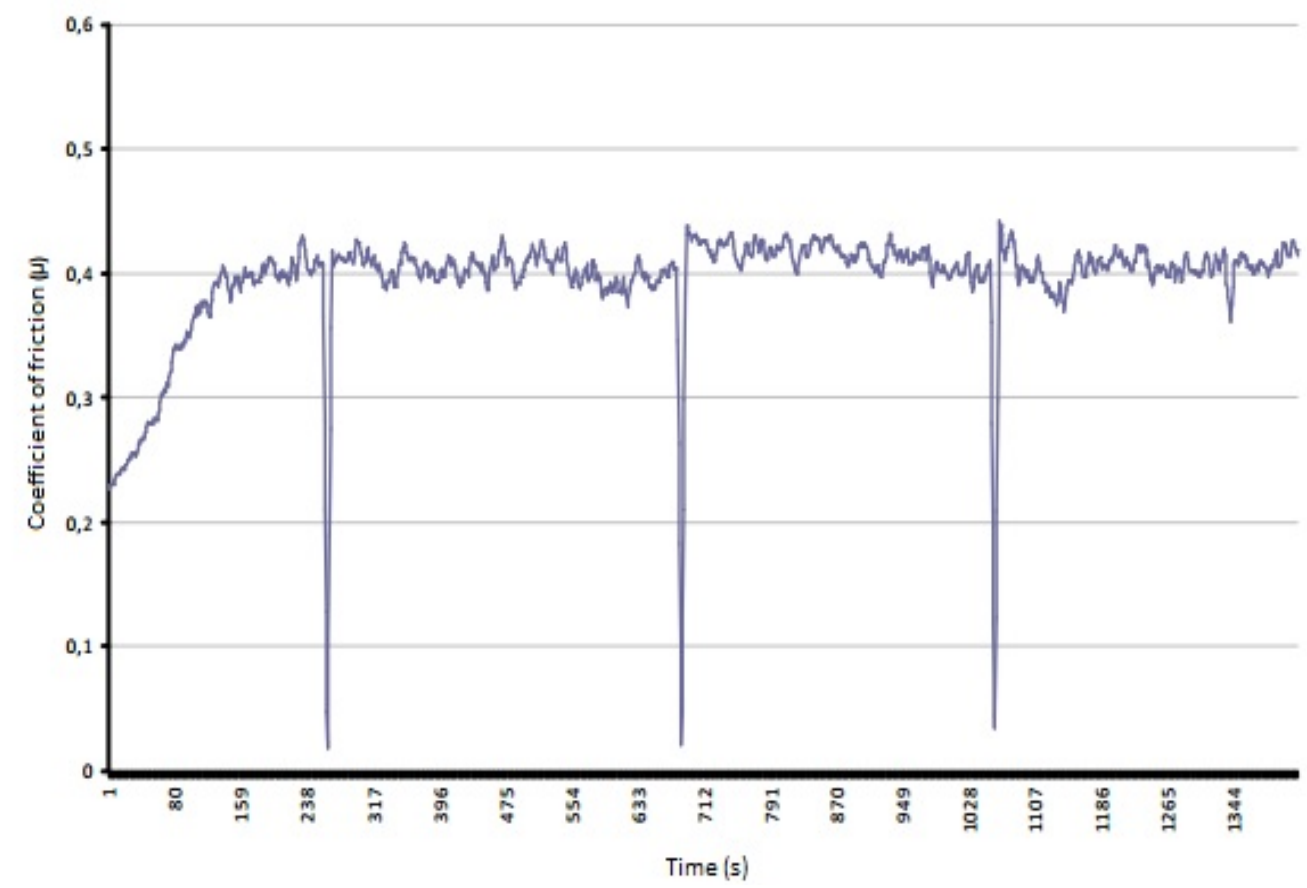

Fig. 9 The coefficient of friction behavior found on the coated surface. 


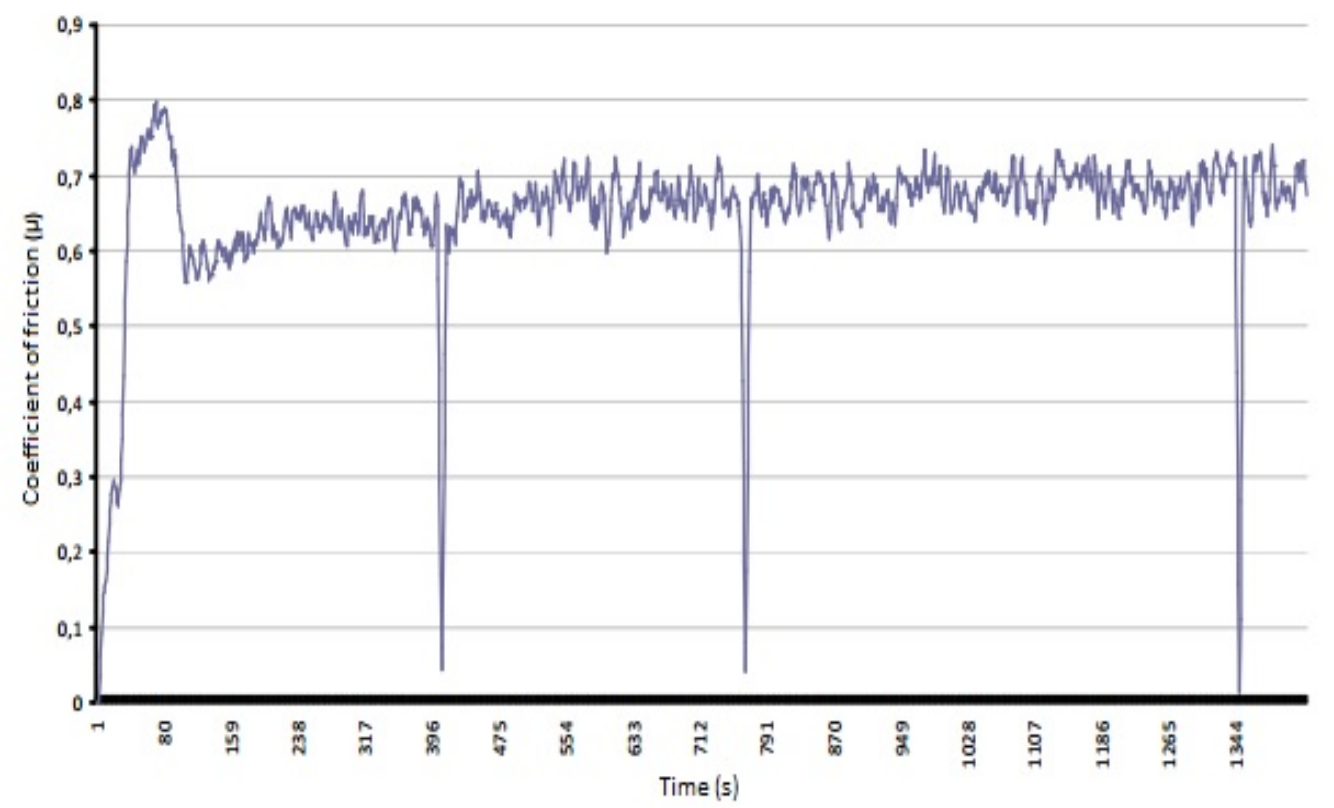

Fig. 10 The coefficient of friction behavior found on the regular surface.

Through laboratory wear test was possible to observe a coefficient of friction with a value of 4.2 on the coated surface, which was lower than the value of 6.6 found on the regular surface. In a qualitative way, the coated sample showed less wear on the pin-on-disc test [12].

\subsection{Production Performance}

Table 4 presents the comparison between the production results obtained with the regular tool and the batch forged with the coated tool.

From the results shown in Table 4 it is possible to observe that the forging using the coated tool enabled a production increase of $37.5 \%$ compared to the conventional process. The production time also showed better results as there was a reduction of $75 \%$ of situations that would cause the machine to remain stopped.

The coated forging die demonstrated a better performance in parts quality and in productivity, which is possible to verify in Table 4 at the waste and tooling activities. Figs. 11 and 12 display one of the last parts of each batch of 900 parts, it is possible to observe that the part from the coated tool batch has better legibility of the printed numbers.

The coated die displayed a more stable behavior related to the manufacturing requirements, which enabled a better performance of all productivity factors.

Table 4 Production line test results.

\begin{tabular}{|l|l|l|l|}
\hline Activities & Coated tool & $\begin{array}{l}\text { Regular } \\
\text { tool }\end{array}$ & $\begin{array}{l}\text { Difference, } \\
\text { using the } \\
\text { regular tool } \\
\text { as reference }\end{array}$ \\
\hline $\begin{array}{l}\text { Total number of } \\
\text { forged parts }\end{array}$ & 1386 & 1008 & +378 \\
\hline $\begin{array}{l}\text { Waste due to } \\
\text { tool-related problems } \\
\text { (number of parts) }\end{array}$ & 0 & 5 & -5 \\
\hline $\begin{array}{l}\text { Production time lost } \\
\text { due to tool-related } \\
\text { problems (minutes) }\end{array}$ & 9 & 36 & -27 \\
\hline $\begin{array}{l}\text { Quality incidents } \\
\text { related to the tool } \\
\text { (number of issues) }\end{array}$ & 0 & 2 & -2 \\
\hline $\begin{array}{l}\text { Suspicion of quality } \\
\text { issues related to the } \\
\text { tool (number of issues) }\end{array}$ & 1 & 3 & -2 \\
\hline
\end{tabular}

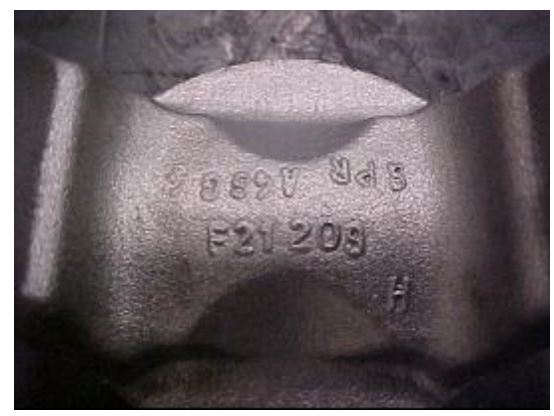

Fig. 11 Photo of one of the last parts of the coated die batch. 


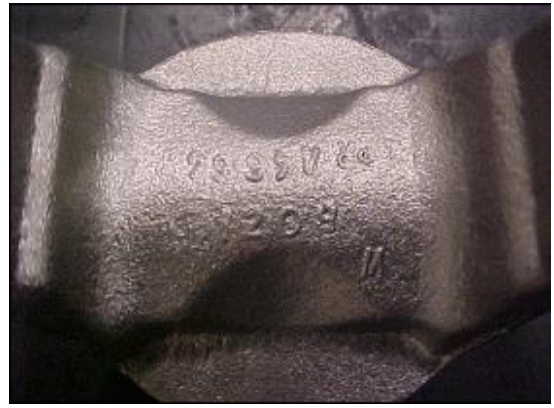

Fig. 12 Photo of one of the last parts of the regular die batch.

\section{Conclusions}

In the production line test, the coated tools featured significant improvement to the process performance, the number of forged parts was about $35 \%$ higher than the number of parts forged with regular tools. The quality aspect also had better results when forging with the coated tools. Based on the results obtained after the production of a batch of parts, it is possible to conclude that, for the financial aspects, the production of parts using HVOF coated dies enables a gain of $30 \%$ compared to the regular process.

\section{Acknowledgements}

We would like to thank the forge division of Dana Albarus from Gravataí and the Rijeza Company from São Leopoldo for the availability to perform production tests and laboratory analysis. We would also like to thank CAPES and CNPQ for research grants.

\section{References}

[1] Selvadurai, U., Hollingsworth, P., Baumann I., Hussong B., Tillmann W., Rausch S., and Biermann, D. 2015. "Influence of the Handling Parameters on Residual Stresses of HVOF-Sprayed WC-12Co Coatings." Surface \& Coatings Technology 268: 30-5.

[2] Barrau, O., Boher, C., Gras, R., and Rezai-Aria, F. 2003. "Analysis of the Friction and Wear Behaviour of Hot Work Tool Steel for Forging." Wear 255: 1444-54.

[3] Lima, C. C., and Trevisan, R. 2007. Aspersão Térmica Fundamentos e Aplicações. São Paulo: Artliber.

[4] Byrer, T. G. 1985. ASM - Forging Handbook. Introduction and Applications. Cleveland: Forging Industry Association.

[5] Schneider, K. E. 2006. Thermal Spraying for Power Generation Components. Weinheim: WILEY-VCH Verlag Gmbh \& Co. KGaA.

[6] Fauchais, P. L., Heberlein, J. V., and Boulos, M. I. 2014. Thermal Spray Fundamentals. New York: Springer.

[7] DIN EN 50320:1999, Wear Terms - Systematic Analysis of Process Classification of Wear Phenomena.

[8] Mobley, R. K., Higgins, L. R., and Wikoff, D. J. 2007. Maintenace Engineering Handbook. Seventh Edition. Tennesse: Mcgraw-Hill Handbooks.

[9] Gadelmawla, E. S., Koura, M. M., Maksoud, T. M., Eleva, I. M., and Soliman, H. H. 2013. "Roughness Parameters." Journal of Materials Processing Technology 123: 123-45.

[10] ASM (American Society of Materials). 1997. Metals Handbook. Vol. 5. Ohio: Surface Engineering.

[11] American Society for Testing Materials. 2008. Astm E 384-89. Standard Test Method for Microindentation Hardness of Materials. Philadelphia, PA.

[12] Fang, W. C. 2015. "Processing Optimization, Surface Properties and Wear Behavior of HVOF Spraying WC-CrC-Ni Coating." Journal of Materials Processing Technology 1: 3561-7. 